\title{
Estimates of the likelihood that a Down's syndrome child of unknown genotype is a consequence of an inherited translocation
}

\author{
SUSAN G ALBRIGHT AND ERNEST B HOOK
}

\begin{abstract}
From the New York State Department of Health, Division of Laboratories and Research, Birth Defects Institute, Albany, New York 12237; and the Department of Pediatrics, Albany Medical College, Albany, New York 12208, USA
\end{abstract}

SUMMARY The proportions of Down's syndrome livebirths associated with a Robertsonian translocation inherited from a carrier parent were estimated from data in the New York State Chromosome Registry and in two previous publications. Indirect estimates were made in each 5-year maternal age interval; these were derived from mutation rates for these translocations and maternal age specific prevalence rates in livebirths. The proportions diminished steadily with increasing maternal age. The ranges for the seven maternal age groups from under 20 to 45 to 49 were: $1 \cdot 1$ to $2 \cdot 8 \%$, 1.0 to $2.7 \%, 0.7$ to $1.8 \%, 0.5$ to $1.3 \%, 0.2$ to $0.4 \%, 0.05$ to $0.1 \%$, and 0.02 to $0.04 \%$. Direct estimates from the observed data could only be attempted for two age groups, women under 30 and those 30 or more. For those under 30 the range in proportions was 0.9 to $1.9 \%$ and for those 30 and over, 0.2 to $0.4 \%$. In general the lowest proportions at any age were derived from New York State data and the highest from Japanese data.

Unbalanced interchange trisomies associated with G21 or D21 Robertsonian translocations account for between 3 and $6 \%$ of all Down's syndrome cases. ${ }^{12}$ Approximately $25 \%$ of these translocations are inherited ${ }^{3} 4$ and about $75 \%$ are new mutants. An important reason for cytogenetic investigation of a patient with a phenotypic diagnosis of Down's syndrome is detection of a familial translocation that may be associated with a high risk of Down's syndrome in future sibs or other relatives of the proband. We present here estimates of the likelihood that an unkaryotyped Down's syndrome patient is a consequence of a familial (inherited) interchange trisomy.

\section{Materials and methods}

The New York State Chromosome Registry, since its inception in 1969, has received reports of chromosome abnormalities from about 25 laboratories which do cytogenetic analysis (see acknowledgements) in New York State. Data reported up to December 1977 on 1968-1977 livebirths are analysed here.

An independent analysis of the data in the Registry on translocation Down's syndrome reReceived for publication 23 October 1979 sulted in an estimated overall mutation rate (for D21 and G21 types combined) of $2.5 \times 10^{-5}$ per gamete for the decade 1968 to 1977 (Hook and Albright, submitted for publication). This rate is slightly higher than that found in the studies of others. Polani et al $^{3}$ estimated a rate of $2.04 \times 10^{-5}$ and Kikuchi et al $^{4}$ a rate of $2.15 \times 10^{-5}$.

The proportion of translocations known to be familial among the total of all translocations whose status could be determined was 0.12 in the Registry, compared to 0.26 and 0.29 in the series of Polani et al and Kikuchi et al, respectively. These differences are probably because of the increase in sporadic interchanges seen in New York State after 1972 (Hook and Albright, submitted for publication). ${ }^{5}$ The prevalence $P$ of familial interchange trisomies in livebirths was estimated as follows:

$$
\mathbf{P}=\frac{(2)(\mathbf{M})\left(\mathbf{P}_{\mathrm{i}}\right)}{\mathbf{P}_{\mathrm{m}}}
$$

where $\mathbf{M}=$ the mutation rate for translocation cases, $P_{m}=$ the ratio of mutant cases to all translocations of known status, and $P_{i}=$ the ratio of inherited cases to all translocations of known status. The latter two variables are from data reported. 
It is assumed in this derivation that the variables $\mathbf{P}$ and $\mathbf{M}$ in livebirths, in the absence of pregnancy termination, have little if any variation with maternal age, in contrast to $47,+21$ which constitutes the vast bulk of the phenotype. For each 5-year maternal age group, the proportion of Down's syndrome cases attributable to an inherited translocation was calculated by dividing $\mathbf{P}$ by the estimated livebirth prevalence rate $(\mathrm{L})$ for all cases of Down's syndrome in livebirths in the same 5-year period. ${ }^{6}$ This method, which may be referred to as the 'indirect' approach, was applied to Registry data as well as data in earlier reports. Alternatively a 'direct' approach was taken by dividing the reported number of familial cases in an age range by the total number of Down's syndrome cases reported in that age range. Because the absolute number reported in any 5 -year period was so small, the direct analysis was limited to two

TABLE 1 Indirect estimates of the proportion of Down's syndrome cases which can be attributed to inherited interchange trisomies by maternal age category

\begin{tabular}{|c|c|c|c|c|c|c|}
\hline Study & $\begin{array}{l}\text { Translocation } \\
\text { mutation rate } \\
\left(\times 10^{-5} \text { per gamete }\right) \\
(M)\end{array}$ & $\begin{array}{l}\text { Proportion } \\
\text { mutant }\left(P_{\mathrm{m}}\right)\end{array}$ & $\begin{array}{l}\text { Prevalence } \\
\text { inherited } \\
\text { cases } \\
\left(\times 10^{-5}\right) \\
(P)\end{array}$ & $\begin{array}{l}\text { Maternal } \\
\text { age }\end{array}$ & $\begin{array}{l}\text { Reference } \\
\text { livebirth } \\
\text { rate } 6 \\
\text { (per 1000) } \\
\text { (L) }\end{array}$ & $\begin{array}{l}\text { Estimated \% } \\
\text { Down's syndrome cases } \\
\text { attributable to } \\
\text { inherited translocation } \\
(P / L)\end{array}$ \\
\hline $\begin{array}{l}\text { New York State } \\
\text { Registry }\end{array}$ & $2 \cdot 5$ & 0.88 & 0.679 & $\begin{array}{c}<20 \\
20-24 \\
25-29 \\
30-34 \\
35-39 \\
40-44 \\
45-49 \\
<30 \\
\geqslant 30 \\
\text { Total }\end{array}$ & $\begin{array}{c}0.63 \\
0.65 \\
0.96 \\
1.38 \\
4.37 \\
13.45 \\
43 \cdot 26 \\
0.771 \\
3.421 \\
1.438\end{array}$ & $\begin{array}{l}1 \cdot 1 \\
1.0 \\
0.7 \\
0.5 \\
0.2 \\
0.05 \\
0.02 \\
0.9 \\
0.2 \\
0.5\end{array}$ \\
\hline Polani et $a l^{3}$ & $2 \cdot 04$ & 0.74 & $1 \cdot 434$ & $\begin{array}{c}<20 \\
20-24 \\
25-29 \\
30-34 \\
35-39 \\
40-44 \\
45-49 \\
<30 \\
\geqslant 30 \\
\text { Total }\end{array}$ & $\begin{array}{c}0.63 \\
0.65 \\
0.96 \\
1.38 \\
4.37 \\
13.45 \\
43 \cdot 26 \\
0.771 \\
3.421 \\
1.438\end{array}$ & $\begin{array}{l}2 \cdot 3 \\
2 \cdot 2 \\
1 \cdot 5 \\
1 \cdot 0 \\
0 \cdot 3 \\
0 \cdot 1 \\
0 \cdot 03 \\
1 \cdot 9 \\
0 \cdot 4 \\
1 \cdot 0\end{array}$ \\
\hline Kikuchi et al4 & $2 \cdot 15$ & 0.71 & $1 \cdot 756$ & $\begin{array}{c}<20 \\
20-24 \\
25-29 \\
30-34 \\
35-39 \\
40-44 \\
45-49 \\
<30 \\
\geqslant 30 \\
\text { Total }\end{array}$ & $\begin{array}{c}0.63 \\
0.65 \\
0.96 \\
1.38 \\
4.37 \\
13.45 \\
43 \cdot 26 \\
0.771 \\
3.421 \\
1.438\end{array}$ & $\begin{array}{l}2 \cdot 8 \\
2 \cdot 7 \\
1 \cdot 8 \\
1 \cdot 3 \\
0 \cdot 4 \\
0 \cdot 1 \\
0 \cdot 04 \\
2 \cdot 3 \\
0 \cdot 5 \\
1 \cdot 2\end{array}$ \\
\hline
\end{tabular}

TABLE 2 Estimates of the proportion of Down's syndrome cases attributable to inherited translocations* $\dagger$

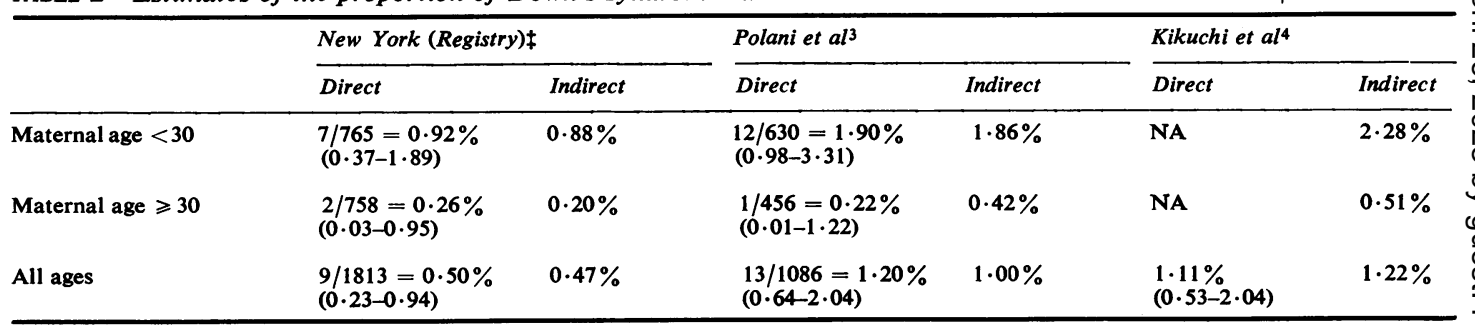

NA, not available from data presented.

* Numbers in parentheses indicate the $95 \%$ confidence limits on the proportions ( $\%)$

†Indirect estimates are those derived using Upstate New York Down's syndrome rates in livebirths as in table 1.

fData reported by December 1977. 
TABLE 3 Range in summary estimates of the proportion of Down's syndrome cases attributable to inherited Robertsonian translocations by maternal age category

\begin{tabular}{llll}
\hline Maternal age & Lowest & Highest \\
\hline$<20$ & $1 \cdot 1 \%$ & - & $2.8 \%$ \\
$20-24$ & $1.0 \%$ & - & $2.7 \%$ \\
$25-29$ & $0.7 \%$ & - & $1.8 \%$ \\
$30-34$ & $0.5 \%$ & - & $1.3 \%$ \\
$35-39$ & $0.2 \%$ & - & $0.4 \%$ \\
$40-44$ & $0.05 \%$ & - & $0.1 \%$ \\
$45-49$ & $0.02 \%$ & - & $0.04 \%$ \\
& & & \\
$\geqslant 30$ & $0.9 \%$ & - & $2.3 \%$ \\
Total & $0.2 \%$ & - & $0.5 \%$ \\
\hline
\end{tabular}

crude age divisions, under 30 , and 30 or over. This approach was taken with the Registry data and with available published data on which this estimate could be made.

\section{Results}

Table 1 presents proportions $(\mathrm{P} / \mathrm{L})$ derived using the indirect approach for the New York State Registry data and for data in the previous reports of others. Table 2 presents those proportions derived using the direct approach and comparisons with the indirect estimates from table 1 . Because each variable used in the indirect estimate has some error associated with it, confidence limits on the final derived indirect estimates presented in tables 1 and 2 are not easily obtained, in contrast to the proportions calculated in the direct approach (table 2). The direct and indirect estimations are not incompatible, however. A summary of the ranges of percentages derived from data in the Registry and in previous reports is shown in table 3.

\section{Discussion}

The prevalence of inherited translocations that has been calculated for each study by the indirect method is quite sensitive to relatively small variations in the mutation rate and in the observed proportion of inherited cases among all Down's syndrome cases. It is noteworthy that the estimated New York State livebirth prevalence of inherited translocations (and therefore the percentage of these at each maternal age category) is less than half those calculated using published data reported by others. This is especially apparent in the percentages calculated for mothers under age 30. The difference is probably because of two factors. There was an increase in mutant cases in New York in recent years but no concomitant increase in the numbers of inherited cases. Additionally, in the Registry experience the ratio of cases with an inherited translocation to all types of Down's syndrome is lower than in published surveys. We suspect this may be the result, at least in part, of selective inclusion in published cytogenetic surveys of familial cases of Down's syndrome. Lastly, sampling fluctuation may contribute. Despite these differences, at least the order of magnitude estimates at each 5-year interval are consistent. The marked decline in the proportion of inherited translocations associated with Down's syndrome with maternal age reflects the very marked increase in 47 , trisomy 21 with maternal age, and the fact that there is little if any dependence on maternal age for the translocation cases, inherited or mutant.

The authors wish to thank Philip K Cross for assistance with the tabulations. New York State laboratories currently affiliated with the New York State Chromosome Registry and their directors are: New York State Birth Defects Institute (Dr I H Porter), State University of New York at Buffalo School of Medicine (Dr R M Bannerman), Columbia University College of Physicians and Surgeons (Dr D Warburton), Grasslands Hospital (Dr P Farnsworth), Letchworth Village (Dr L R Shapiro), Jewish Hospital and Medical Center of Brooklyn (Dr R Verma), Mt Sinai School of Medicine (Dr R J Desnick), New York Blood Center (Dr J German), NYS Psychiatric Institute (Dr J D Rainer), University of Rochester (Dr R Doherty), State University of New York at Buffalo, Children's Hospital (Dr R Neu), State University of New York at Syracuse Upstate Medical Center (Dr L Gardner), University of Rochester Clinical Genetics Center (Dr P L Townes), Albert Einstein College of Medicine (Dr H M Nitowsky), Beth Israel Medical Center (Dr H Kim), Mental Retardation Institute (Dr P L Wilmot), State University of New York Downstate Medical Center (Dr G Solish), Nassau County Medical Center (Dr C Trunca), New York University Medical Center (Dr S R Wolman), Brooklyn-Cumberland Medical Center (Dr K David), Long Island Jewish-Hillside Medical Center (Dr E Lieber), North Shore Hospital (Dr J Davis), New York Institute for Basic Research in Mental Retardation (Dr E C Jenkins), Brookdale Hospital Medical Center (Dr E Schutta). The Registry has been supported by the National Foundation-March of Dimes.

\footnotetext{
References

1 Hamerton JL. Human cytogenetics. In: Clinical cytogenetics. vol II. New York: Academic Press, 1971.

2 Huang SW, Emanual I, Lo J, Liao SK, Hsu CC. A cytogenetic study of 77 Chinese children with Down's syndrome. J Ment Defic Res 1967;11:147-52.
} 
3 Polani PE, Hamerton JL, Gianelli F, Carter CO. Cytogenetics of Down's syndrome (mongolism). III. Frequency of interchange trisomies and mutation rate of chromosome interchanges. Cytogenetics 1965;4:193-206.

4 Kikuchi Y, Oishi H, Tonomura A, et al. Translocation Down's syndrome in Japan: its frequency. Jpn J Hum Genet 1969;14:93-106.

5 Hook EB. The ratio of de novo unbalanced translocations to 47, trisomy 21 Down syndrome: a new method for human mutation surveillance and an apparent recent change in mutation rate resulting in human interchange trisomies in one jurisdiction. Mutat Res 1978;52:427-39.
6 Hook EB, Chambers GM. Estimated rates of Down $\frac{\mathbb{Q}}{2}$ syndrome in livebirths by one year maternal age intervals $\mathbb{D}$ for mothers aged $20-49$ in a New York State study: implications of the risk figures for genetic counseling and cost-benefit analysis of prenatal diagnosis programs Birth Defects 1977;13, No 3A:123-41.

Requests for reprints to Dr Ernest B Hook, Birth Defects Institute, Albany Medical College, Albany, New York 12208, USA.

\section{y,}

